\title{
Transitory Control Algorithm of Reactive Current for LSC of BDFIG Based Fuzzy Controller
}

\author{
S. Siva Prasad, D. Lakshmi, C.N. Ravi
}

\begin{abstract}
The main aim of the paper is transitory mechanism process of the reactive current through the line-side converters of BDFIG based fuzzy controller. In individual process, the quality of voltage waveform on point of mutual connection would be intensely affected owing to responsive power alteration of load. The LSC could not work normally because of the PCC voltage is greater than voltage of DC-link. To mitigate this issues, various control schemes i.e., predictive direct voltage control and direct current control are generally established in machine_adjacent converter to supply the reactive power. The line side converter could support in controlling the voltage at point of common coupling variations through providing or observing reactive current. This proposed paper examines load transient state and voltage of PCC is quickly joined to the stator PW. Formerly the LSC controllability throughout the voltage swell of PCC is studied when load is separated commencing the stator $P W$. In this paper a High HVRT control scheme with fuzzy controller is suggested through utilizing the $L S C$ reactive current. The simulation results of proposed method is verified by MATLAB/SIMULINK environment.
\end{abstract}

Key words: Brushless Doubly Fed Induction Generator, PCC, Line Side Converter (LSC), HVRT, Fuzzy controller.

\section{INTRODUCTION}

The advantages of Brushless doubly-fed induction generator (BDFIG) such as it needs a low-power as compared with the nominal machine. Besides, due to the absence of slip rings\& brush gear which increases the reliability with minimum maintenance. With the feature of independent control of reactive \& active power in BDFIG as generation of power in various applications like ship shaft generation systems. BDFIG mainly consists of stator windings of 3 -stage. First one is winding of stator utilized to generate power while other is stator winding utilized to control stator to vary voltage \& supply frequency. Another stator windings called stator control windings (CW) gets energized from variable frequency power converter \& variable voltage connected to stator. To join or couple the windings of two stator, a winding of rotor (RW) is utilized. In the standby mode brushless doubly fed induction generator scheme, generator would be regulated to give constant voltage to stator to support loads, the voltage fluctuations across the loads appeared. In this case, load was separated or associated

Revised Manuscript Received on December 30, 2019.

Dr. S. Siva Prasad, Professor, Department of Electrical and Electronics Engineering, Vidya Jyothi Institute of Technology, Hyderabad, Telangana State, India. Email:drsyamalasivaprasad@gmail.com

Dr. D. Lakshmi, Associate Professor, Department of Electrical and Electronics Engineering,, AMET Deemed to be an University, Chennai, Tamilnadu, India. Email:lakshmiee@gmail.com

Dr. C.N. Ravi, Professor, Department of Electrical and Electronics Engineering, Vidya Jyothi Institute of Technology, Hyderabad, Telangana State, India. Email: dr.ravicn@gmail.com from PCC. The variations in voltage decreases the enactment of load is associated to PCC \& pulsations in torque.

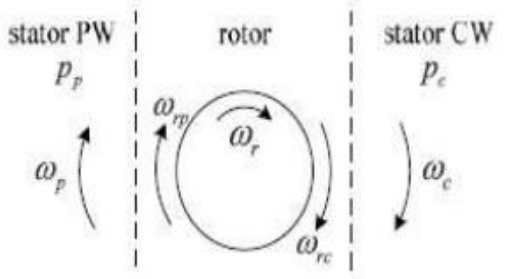

Fig. 1. Doubly-fed mode of BDFIG

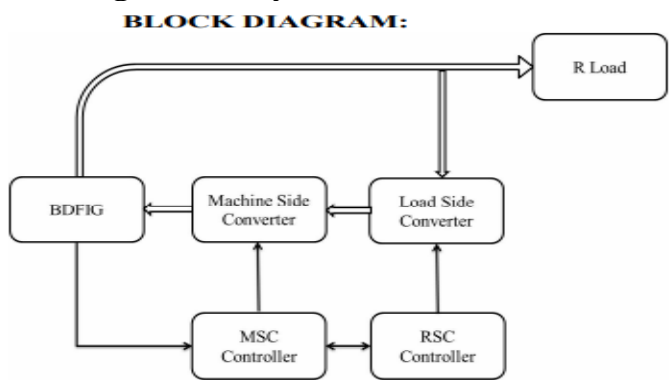

\section{WIND TURBINES}

Basically, there are two types of wind turbine in relation to their rotor settings. They are:

1. Vertical-axis rotors, \&

2. Horizontal-axis rotors.

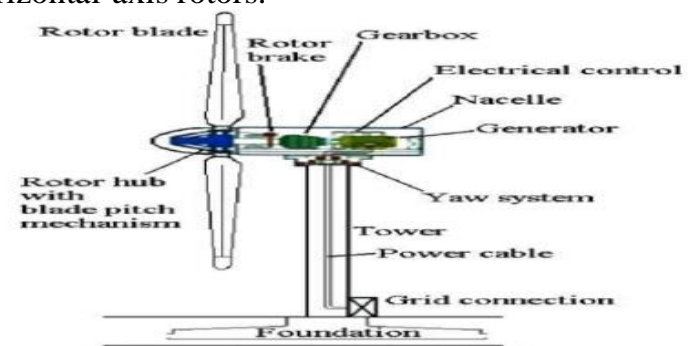

Fig: 2 Horizontal axis of wind turbine.

\section{Number of Rotor blades}

In modern aero generators, 3-bladed rotors are used common. As compared with 3-bladed, 2-bladed \& 1-bladed concept has advantage of denoting a saving of weight $\&$ cost of rotor. Anyway, the few rotor blades imparts an increase in speed or longer chord is required to get same energy in same size. With the 2 blades will get fluctuations in load due to variations in inertia, depending on the position (vertical or horizontal) or on wind speed variation, the blade is putting downward or upward. So, one \& 2 bladed concepts generally adopted in teetering hubs, that the rotor fixed to the main shaft. 
This design permits the rotor to teeter to minimize the unbalanced loads. 1 bladed wind turbines are less widespread compared with 2-bladed turbines. This is due to addition of greater rotational speed which leads to more visual intrusion $\&$ more noise problems, \& require a counter weight to balance the position of blade. The turbine can be fixed to the generator to give an indirect with the help of mechanical accumulator or battery. From this, we can understood that control of generator is independent of operation of turbine.

The generator basically uses wind machines such as

1) Induction $A C$ generator

2) Synchronous AC generator

3) Variable speed generator

Offshore generation of wind power refers to the construction of wind turbines in the bodies of water to produce electricity. Offshore is mainly used in marine industry \& it includes fjords, lakes \& sheltered coastal areas \& deep-water areas.

\section{PROJECT DESCRIPTION}

\section{A.CONFIGURATION OF THE BDFIG}

Brushless doubly Fed Induction Generator (BDFIG) mainly contains two stator windings isolated electrically known as Stator CW \& Stator PW. The main function of stator PW gives a pp (pole-pair) rotating field at wp speed \& stator CW gives a pc pole-pair field rotates at wc speed. In order to couple the windings of stator, RW is specially designed \& implemented. The BDFIG usually works in synchronous mode known as doubly-fed mode as depicted [3] in Figure.1

From Figure.1, rotor winding generate the prompted current with wp angular speed\& wrc with respect to stator control winding $\&$ power winding. Angular speed in references of rotor frame given as

$$
\begin{array}{r}
\text { Grp }=\mathrm{GOp}-\mathrm{PGOr} \\
\mathrm{Grc}=\mathrm{GOc}-\mathrm{PcGOr} . . . .
\end{array}
$$

For unique fixed of RW, the similar flow of currents which is needed that Gorp $=-$ GOrc. The angular speed GOr is given by

$$
\mathrm{GOr}=\frac{\mathrm{wp}+\mathrm{Wc}}{P p+P c}
$$

Here,

GOc \& GDp are angular speed of stator CW \& stator PW respectively

From equation (2), it is observed that variable speed Gor of BDFIG, GDp is kept constant by varying Go. This is the operation of BDFIG. When the magnitude of angular speed gradually reduces to zero, the angular speed Gr is represented by

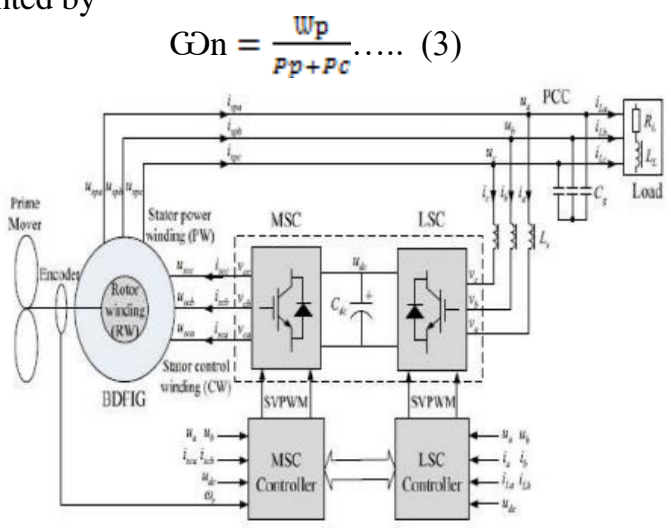

Fig. 3 Configuration of BDFIG standalone supplying inductive-resistive load

Fig. 3 explains the structure diagram of BDFIG system that give 3-stageR-L load. From Figure.3, power winding of stator is associated to load directly \& provides power to converter. Control winding of stator is gets supply with two back-to-back converters consists of MSC\&LSC converters in common dc-link \& connected to PCC \& stator PW.

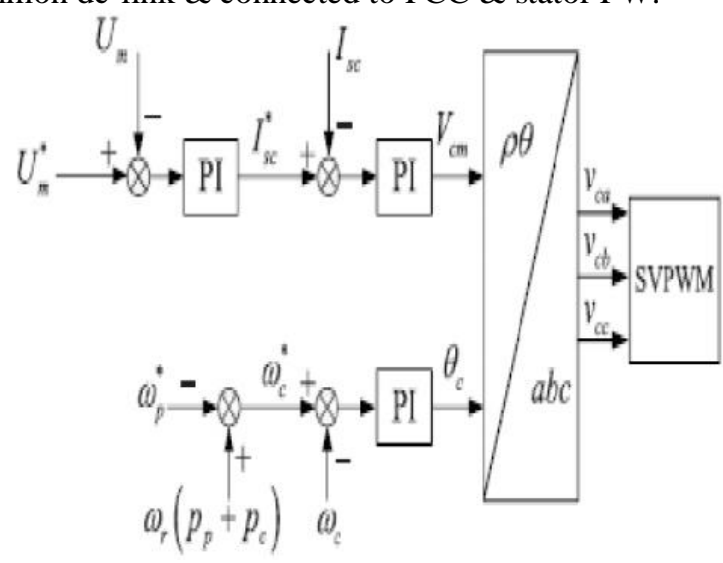

Fig. 4. BDFIG Scalar Control Diagram

From Figure.4, a Y-coupled capacitor filtering is connected with stator PW o/p of BDFIG. The main function of capacitor reduce ripples in PW voltage of stator \& filter the harmonics generated by LSS works on the principle of PWM (Pulse Width Modulation) technique. The inverter of Siemens utilized to reproduce different speeds variation of prime forces. RL \& LL are resistance \& inductive equivalent of load respectively. Generally, the main function of MSC to control the current of stator $\mathrm{CW}$ to control the power winding voltage of stator. The main objective of this project is regulate the line side converter reactive current.

In Figure. $4 \mathrm{Um}$ is magnitude of PCC voltage u\&Isc is magnitude of stator $\mathrm{CW}$ current is c.

$\mathrm{Vcm} \& \theta \mathrm{c}$ are magnitude of phase voltage Vic \&segment angle of machine side converter correspondingly. When magnitude of voltage of point of common coupling is shorter than base value, stator current $\mathrm{CW}$ would improve $\&$ vice versa. It is one of the basic \&dependable process in BDFIG to eliminate motor parameters. The present method is used for less-enactment applications such as pumps \& fans.

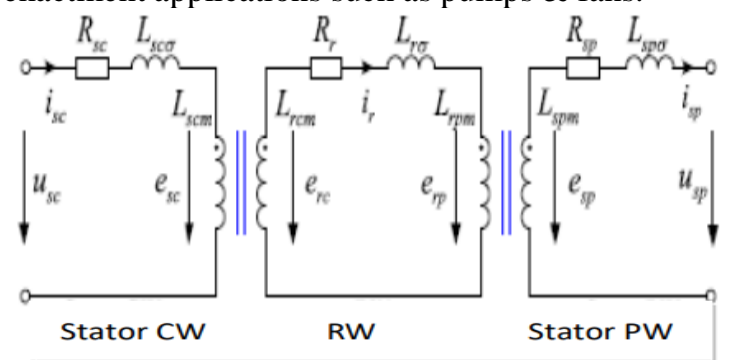

Fig.5. brush less doubly fed induction generator Per-phase stable-state corresponding circuit

\section{TRANSIENT REACTIVE CURRENT RECOMPENSEPROCESS IN CASE OF THE L- LOAD CONNECTION} Inductive_Load_Connection:

The operation conditions of BDFIG \& its connected converters can be fetched with assistance of corresponding path. Fig.5 illustrates about BDFIG per-stage stable-state circuit [16].
Eyes Intelligence Engineering \& Sciences Publication 
So from side power winding of stator, the equivalent network for the combination of emf represented by power winding of stator leakage inductance \&resistance indicated by Lspo \& Rsp respectively. Ignoring all losses in BDFIG, the power balance expression given as

Here $\mathrm{Sb}$ is slip of BDFIG.

The output current from stator PW ispa can be expressed as:

$$
\mathrm{Ia}=\mathrm{sb} \text { ispa } \cos \theta \mathrm{p} \text {. }
$$

Here, $\theta \mathrm{p}$ is stator PW power factor angle

LSC could be observed as a current regulated source. Because MSC \& LSC are combined through a common dc-link capacitor \& could be de-coupled via Cdc, MSC isn't measured in analysis of LSC circuit. A-stage corresponding circuit separate BDFIG framework observed from power winding of stator side is indicated in Figure.6. In Figure.6, iLa is a-phase current of load \&ua is the a-phase PCC voltages.

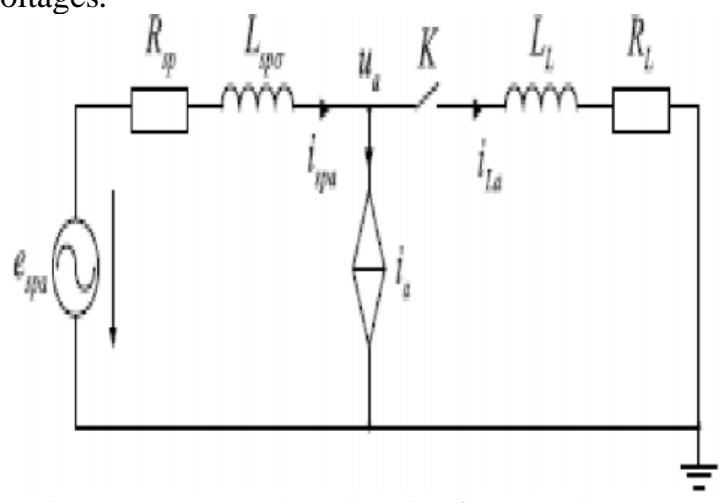

Fig. 6corresponding circuit of phase-A the separate BDFIG framework.

Considering the primary angle of phase-a voltage as the ref angle, espa in time area is defined as listed below:

$$
\operatorname{Espa}(\mathrm{t})=\mathrm{Um} \cos (\mathrm{wt})
$$

Here,

GO \& Um are angular frequency \& amplitude of voltage phase respectively. Espa is composite frequency area is reduced with Laplace conversion.

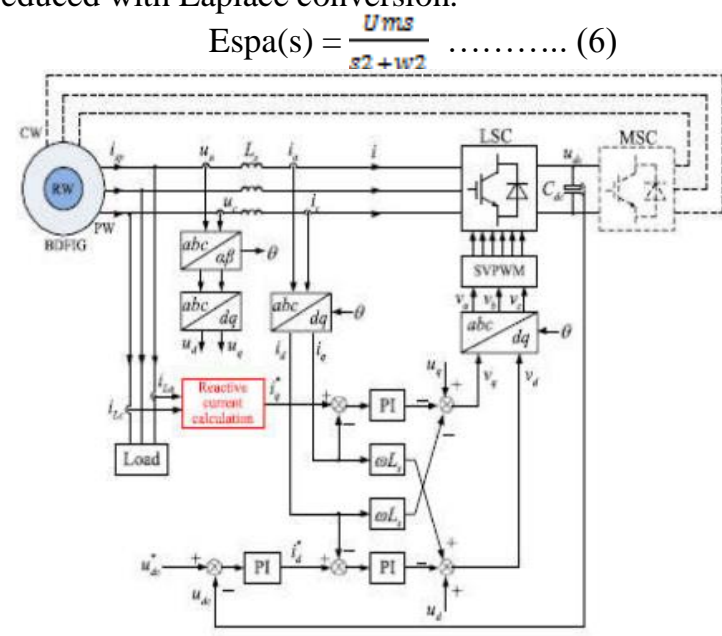

Fig.7. Describes about control diagram of LSC with principle of compensation of reactive current

\section{B. Based on V-I Doubly Closed Loop the compensation in Transient Reactive Current}

With increases in regulates the bandwidth of LSC, line side converter responds to alteration of voltage at point of common coupling allowing to it. It was easier\& simpler to

$$
\text { Psc }=\text { sbPsp. }
$$

select the line side converter to compensate the reactive currents of the load. By performing the voltage-oriented of PCC reference frame, controller schemes of line side converter implements current \&voltage dual closed-loop arrangement indicated in Figure. 7 [19]. In Figure. 7, phase-angle $\theta$ for synchronized methods are predictable with single synchronous orientation frame PLL [20]. With conventional PI controller, o/p of voltage loop is fed back as $\mathrm{d}$-axis reference current to control voltage of dc-link, \& negative reactive element of load current iLq is conveyed as q-axis reference currents to recompense for reactive power winding of stator current produced by load. While the L-load is associated to the BDFIG power winding of stator, load reactive current is expected \&conferring to the IRP concept. Then, the line side converter can delivers reactive currents to the load and help in enhancing the PCC variations in voltage.

\section{C.TRANSIENT REACTIVE CURRENT REGULATE AFTER SUDDEN LOAD INTERRUPTION}

\section{a) Reactive}

In LSC, during swell of voltage current control method is achieved at PCC, while the load is disconnected or connected abruptly from stator PW. Due to this voltage swell $1 \&$ abrupt interruption in the supply of current. The voltage swell leads to LSC uncontrollable which limits dc-link voltage.

$$
\mathrm{Um}=\mathrm{Rsid}+\mathrm{Ls} \frac{\mathrm{did}}{d t}-\mathrm{GOl} \text { siq }+\mathrm{Vd} \ldots \ldots \text { (7) }
$$

Here Rs, Ls are LSC filter resistance \& inductance respectively

By ignoring the resistance Rs \& operating under power factor unity, the correlation of LSC space vectors in steady state is expressed as

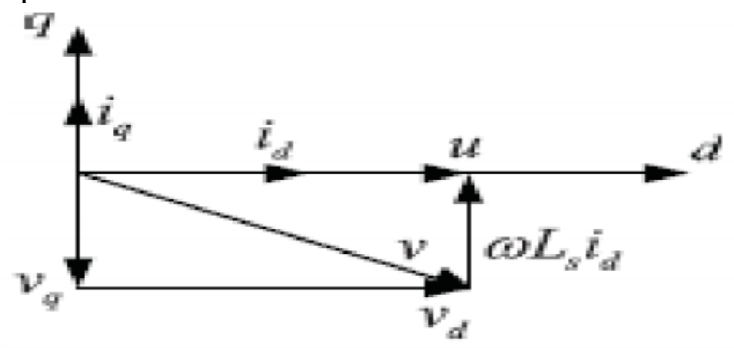

Fig.8. simplified Voltage vector space diagram of the LSC

$$
\begin{gathered}
\mathrm{Ud}=\mathrm{Um}+\mathrm{GOLsIq} \\
\mathrm{Vq}=-\mathrm{G} \text {. }
\end{gathered}
$$

From the diagram described as Fig. 14. By considering the principle of modulation, the voltages of line side converter has to be minimized.

$$
\mathrm{V}=\sqrt{V d^{2}+V q^{2}} \leq \frac{w d c}{\mathrm{~m}} \ldots .
$$

Here, $\mathrm{m}$ is modulation index $\& \mathrm{~m}=2$ for SPWM technique $\mathrm{M}=\sqrt{3}$ SVPWM technique. By combining the equations (8) $\&(9)$, the lower limit for voltage of dc-link capacitor of LSC

$$
\sqrt{(U m+\mathrm{WLsiq}) 2+(\mathrm{WLsid}) 2} \leq \frac{\text { wde }}{\mathrm{m}}
$$

Based on equation (4), id will enhance \& load becomes high. From equation (10) when the load is larger, dc-link voltage is also larger to be required. Even under no-load condition also, dc-link voltage set to minimum Um \& magnitude of Voltage PCC should be minimum. In order to reduce the study, 


\section{Transitory Control Algorithm of Reactive Current for LSC of BDFIG Based Fuzzy Controller}

line side converter is used to reduce total reactive currents generated by all inductive loads. So, in the condition of steady state, the active component of current ispd in the PW stator only \& reactive component of current must be zero. In the duration, the main function of MSC is used to adjust the level of voltage at point of common coupling to chosen value $\mathrm{Um}$, so, the real component of current can be represented as

$$
\mathrm{iLd}=\frac{2}{\mathrm{a}} \frac{P L}{U d}=\frac{2}{\mathrm{a}} \frac{P L}{U m}
$$

Here PL is real load power

Here the load is separated abruptly from power winding of stator, then current at load is remove. So $\Delta \mathrm{ispq}=\mathrm{iLd}$. The voltage swell across PCC can be expressed as:

$$
\Delta \mathrm{ud}=\mathrm{Rsp} \Delta \mathrm{ispd}+\mathrm{Lspo} \frac{\Delta \text { ispd }}{\Delta \mathrm{t}}=\frac{2}{\mathrm{a}} \frac{\mathrm{RgpRL}}{\mathrm{Um}}+\frac{2}{\mathrm{a}} \frac{\mathrm{Lspo} P L}{\mathrm{Um} \Delta \mathrm{t}} .
$$

Here

$\mathrm{Um}$ is instantaneous magnitude of voltage phase at PCC

Um is evaluated Voltage.

$\mathrm{K}$ ensures does not cross the higher value of current imax of line side converter. With consideration of regulation of brushless doubly fed induction generator framework, the voltage o/p across power winding will be controlled current, Imax of LSC. In brushless doubly fed induction generator framework, power winding voltage output will reduced to evaluated value in stable state. After, iq will send back to stable state. Line side converter is controlled in the voltage swell.

b) Transient output voltage of DC-link through the period of Sudden unload:

Utilizing (7), the affiliation of LSC space vectors of voltage in the state of transient could be attained as

$$
\frac{d i d}{d t},=\frac{\text { Wm-wd }+ \text { WLsiq }}{L s}
$$

In the equation mentioned above, it can visualized which if the fast transient output of real current id, the increasing \& decreasing slopes of active current id will be greater [28]. In [31], the Ls \& Um are constant. Maximum voltage needed for inductor Ls for transient output should decrease \& LSC voltage $\mathrm{Vd}$ must be increased upto maximum magnitude. So, the minimum time required to track the base current can be estimated as:

$$
\Delta \mathrm{T}=\mathrm{Ls} . \frac{\mathrm{id} \cdot \mathrm{-id}}{\text { Vdmax-Wisiq }- \text { Um }}
$$

In the above mentioned equation,

Vdmax is the generation of voltage by LSC upto the maximum value

In anyway, the Vdmax (voltage maximum value) is limited as (9) if we use Pulse Width Modulation (PWM) technique. So the magnitude of (Vdmax -WLs iq - Um) is small \& $\Delta \mathrm{T}$ changes greater value. So, the reference value of $d$-axis current reduces, \& regulation is decreased slowly because of constraints of voltage across the converter. It leads to the swell of voltage in dc link for period of short (transient). However, the process changes big serious issues if the voltage in PCC becomes higher value.

From the equation mentioned in (14), we can observe the reactive current iq changes to negative value i.e. decreasing slope of magnitude of active current id \& slowly it becomes higher value. Since, by using the magnitude of negative value of current at q-axis, short duration is probable \& the value of voltage in dc-link becomes fast to track the base value. The simulation obtained in HVRT by the control approaches of line side converter swell in the value of voltage across the PCC will be produced when load is disconnected abruptly.

\section{FUZZY LOGIC}

In the present scenario, wide variety \& numerous application in fuzzy logic increased drastically. The wide range of applications such as camcorders, microwave ovens, cameras \& washing machines, portfolio selection, medical instrumentation etc.

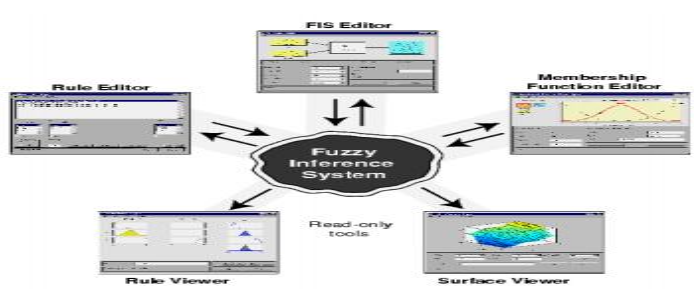

Fig.9 Fuzzy Logic Primary GUI Tool

Fig.9 reveals the 5 primary GUIs can connect \& exchange information. Among 5 GUIs, Any GUI can write \& read both to workspace to load the disc. FIS Editor conserves the equal problems of framework; i.e. How input \& output variables? What are their names? Fuzzy Logic Toolbox gives infinite number of inputs. But the number of inputs limited by memory of machine. If input number is very large, number of functions is also high, it leads to difficult to analyze the FIS with GUI tools.

\section{FIS EDITOR}

In this, building a new fuzzy interference system through scratch. In order to save time $\&$ follow fastly, you can load \& build fuzzy tipper \& that will load FIS related with extension file tipper. fis \& start the FIS Editor. In the first, then you need to build rules \& constructing functions again $\&$ again.

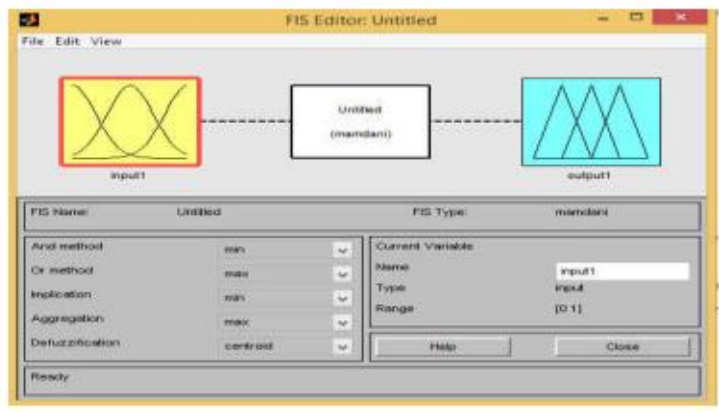

\section{Figure 10. FIS Editor}

In the Figure. 10uploaded to denote new names of the input \& output variables. There is new variable in workspace known as "tipper" which consists information about the entire structure.

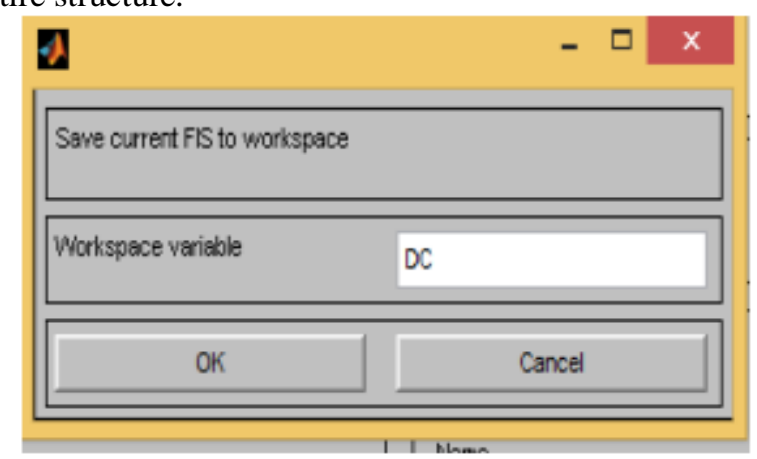

Figure.11'Showshow save to workspace as...' window
Eyes Intelligence Engineering \& Sciences Publication 
By clicking ok workspace will be save with a fresh term\& you can also retitle the structure if you want. The window will be indicated in Figure 11.

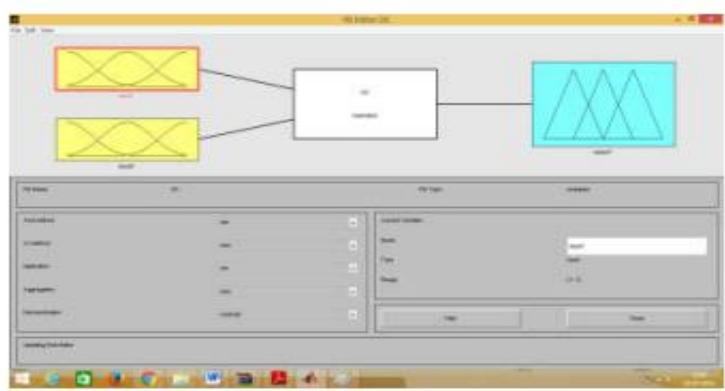

Figure.12Efficient FIS Editor.

Figure. 12gives the interpretation option in lesser left in the defaulting situation. If you entered total info required for specific GUI.

\section{EDITOR FUNCTION OF MEMBERSHIP}

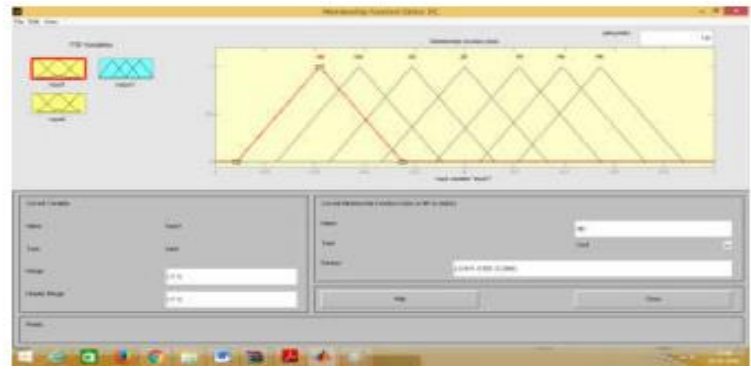

Figure 13. Editor Function of Membership

Figure. 13 Membership Editor Function shares some features with the FIS Editor. Actually, 5 basic GUI tools, status lines, close buttons menu options \& help.

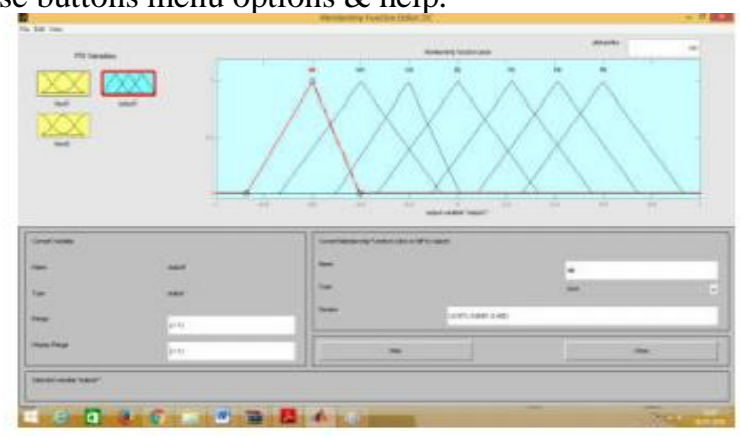

Figure.14 Efficient Membership Purpose Editor.

In Figure 14 when you click on the Membership Function Editor \& open it to work on a fuzzy inference system which doesn't exist in workspace, there is no membership functions connected with variables that you have selected with FIS Editor.

Tab: 1 Rules used in Fuzzy System

\begin{tabular}{|c|c|c|c|c|c|c|c|} 
& $\mathrm{NB}$ & $\mathrm{NM}$ & $\mathrm{NS}$ & ZE & $\mathrm{PS}$ & $\mathrm{PM}$ & $\mathrm{PB}$ \\
\hline $\mathrm{NB}$ & $\mathrm{NB}$ & $\mathrm{NB}$ & $\mathrm{NB}$ & $\mathrm{NB}$ & $\mathrm{NM}$ & $\mathrm{NS}$ & ZE \\
\hline $\mathrm{NM}$ & $\mathrm{NB}$ & $\mathrm{NB}$ & $\mathrm{NB}$ & $\mathrm{NM}$ & $\mathrm{NS}$ & ZE & $\mathrm{PS}$ \\
\hline $\mathrm{NS}$ & $\mathrm{NB}$ & $\mathrm{NB}$ & $\mathrm{NM}$ & $\mathrm{NS}$ & ZE & $\mathrm{PS}$ & $\mathrm{PM}$ \\
\hline ZE & $\mathrm{NB}$ & $\mathrm{NM}$ & $\mathrm{NS}$ & ZE & $\mathrm{PS}$ & $\mathrm{PM}$ & $\mathrm{PB}$ \\
\hline $\mathrm{PS}$ & $\mathrm{NM}$ & $\mathrm{NS}$ & $\mathrm{ZE}$ & $\mathrm{PS}$ & $\mathrm{PM}$ & $\mathrm{PB}$ & $\mathrm{PB}$ \\
\hline $\mathrm{PM}$ & $\mathrm{NS}$ & $\mathrm{ZE}$ & $\mathrm{PS}$ & $\mathrm{PM}$ & $\mathrm{PB}$ & $\mathrm{PB}$ & $\mathrm{PB}$ \\
\hline $\mathrm{PB}$ & ZE & $\mathrm{PS}$ & $\mathrm{PM}$ & $\mathrm{PB}$ & $\mathrm{PB}$ & $\mathrm{PB}$ & $\mathrm{PB}$ \\
\hline
\end{tabular}

Table describes about fuzzy logic rules listed above. Rule Editor has special tools like FIS Editor including status line \& menu bar.

\section{SIMULATION RESULTS}

Fig. 15 indicates the MATLAB/SIMULINK circuit diagram of proposed system with fuzzy controller. It contains stator CW\&PW, machine side converter, line side converter, brush less doubly fed induction generator \& three -stage load Fig. 16 indicates the Voltage at point of common coupling reactive current control without recompense, Fig. 17 indicates voltage at point of common coupling reactive current regulate with fully recompense with fuzzy controller\&Fig. 18 indicates the voltage at point of common coupling reactive current regulate with partly recompense

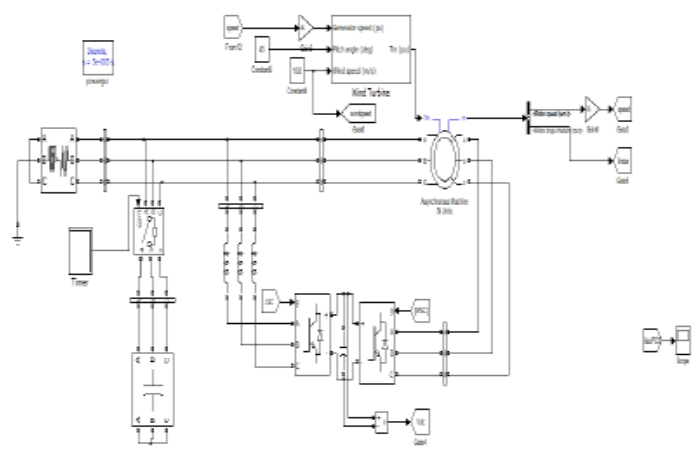

Fig.15 MATLAB/SIMULINK circuit illustration of the proposed system

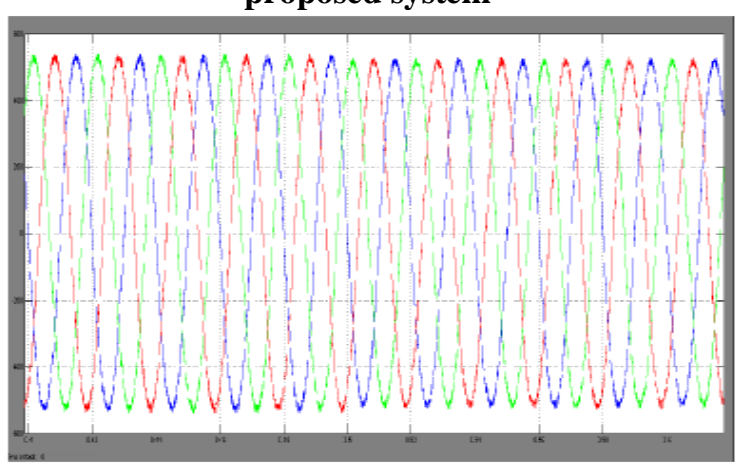

Fig. 16 Voltage at point of common coupling reactive current regulate without recompense with fuzzy controller

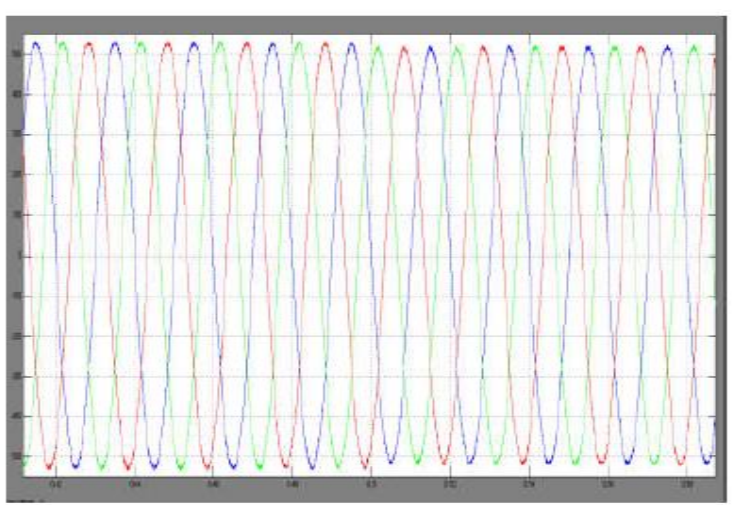

Fig. 17 Voltage at point of common coupling reactive current regulate with fully recompense with fuzzy controller. 


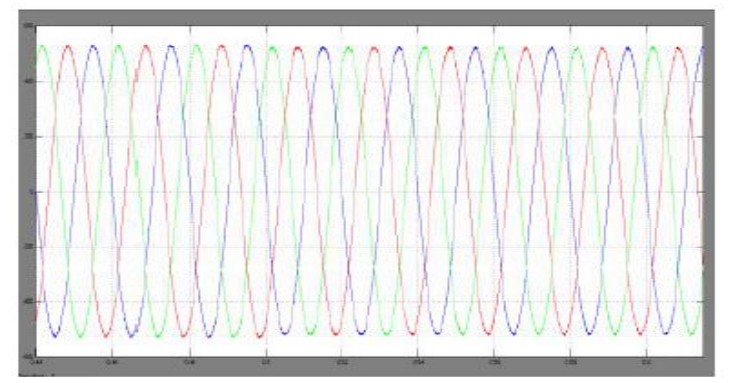

Fig.18 voltage at point of common coupling reactive current regulate with partly recompense

Fig 19 depicts the normal working of LSCs. It can be observed that LSC failed to control value of voltage in dc-link \& current more than the converter rating more. In any way, the transient current taken or inject into PCC, the line side converter can remain controllable under the HVRT control present existing method in Fig. 20.

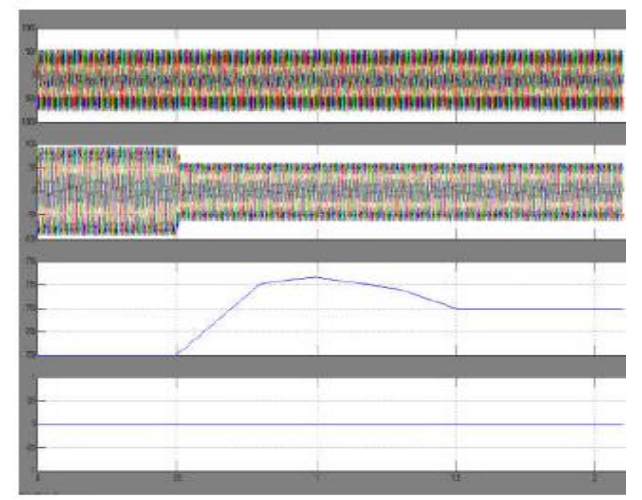

Fig.19 Simulation waveforms of disconnected load from power winding traditional process

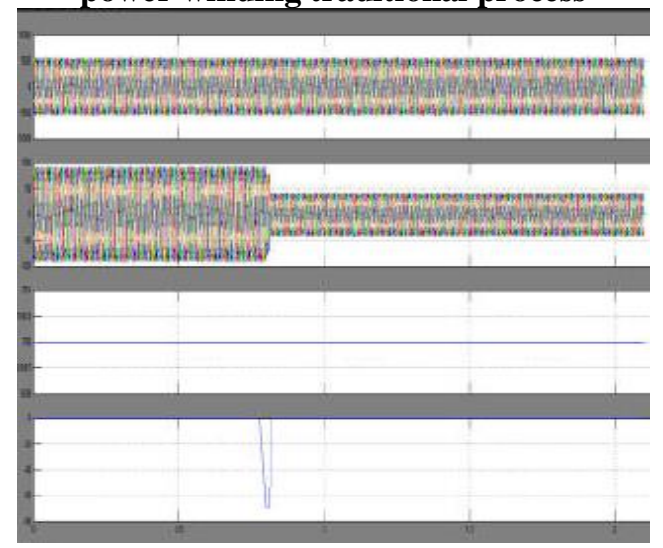

Fig.20 Simulation results of disconnected load from power winding suggested HVRT control

\section{CONCLUSION}

In the suggested paper the temporary reactive current control method for an individual brushless doubly fed induction generator framework to enhances the enactment of the point of common coupling voltage $\&$ the line side converter controllability. The stator current of power winding \& point of common coupling voltages are carried-out while R-L load is quickly linked to BDFIG. It outcomes in distortion \& voltage drip bat point of common coupling, \& if simply important positive sequence of reactive load current is utilized as a mention values of q-axis current regulate loop in line side converter, the voltage of stator could be suggestively recompensed. Additional, the line side converter controllability with incomplete assessment measured throughout the voltage at point of common coupling swell was evaluated. The proposed HVRT control scheme of line side converter is suggested by utilizing the line side converter reactive current, \& it similarly enhances the fast reaction $\&$ the voltage of dc link in transitory section. In the proposed system a High voltage ride through control scheme with fuzzy controller is suggested through utilizing the LSC reactive current.

\section{REFERENCES}

1. A. Zhang, X. Wang, W. Jia,\&Y. Mama, "Backhanded stator-amounts control for the brushless doubly sustained enlistment machine," IEEE Trans. Power Electron., vol. 29, no. 3, pp. 1392-1401, Mar. 2014.

2. X. Chen, X. Wang,\&F. Xiong, "Exploration on Excitation control for standalone wound or brushless doubly fed generator system," in Proc. IEEE 2013 Int. Conf. Electr. Mach. Syst., 2013, pp. 663-667.

3. F. Xiong\&X. Wang, "Structure execution investigation of a brushless doubly-fed machine for standalone ship shaft generator systems," pinprick. IEEE Electr. Contr. Eng. Conf., 2011, pp. 2114-2117.

4. S.Shao,E.Abdi,F.Barati,andR.McMahon,"Stator flux- oriented vector control for brushless doubly sustained enlistment generator," IEEE Trans. Ind. Electron., vol. 56, no. 10, pp. 4220-4228, Oct. 2009.

5. V. E. Wagner, "Impact of music on hardware," IEEE Trans. Power Del., vol. 8, no. 2, pp. 672-680, Apr. 1993.

6. K. Protsenko \& D. Xu, "Displaying control of brushless doubly-sustained enlistment generators in wind vitality applications," IEEE Trans. Power Electron., vol. 23, no. 3, pp. 1191-1197, May 2008.

7. M. Z. Sod, I. Erlich,\&S. Engelh, "Improving the receptive power capacity of the DFIG-based breeze turbine during activity around the synchronous speed," IEEE Trans. Power Convers., vol. 28 no. 3, pp. 736-745, Sep. 2013

8. G. Y. Jeong, T. J. Park, \&B. H. Kwon, "Line voltage-sensor less dynamic power channel for responsive control remuneration," IEE Proc. Electr. Power Appl., vol. 147 no. 5, pp. 385-390, Sep. 2000.

9. V. T. Phan \& H. H. Lee, "Control procedure for consonant disposal in remain solitary DFIG applications with nonlinear burdens," IEEE Trans. Power Electron., vol. 26, no. 9, pp. 2662-2675, Sep. 2011.

10. P. Verdelho \&G. D. Marque, "DC voltage control \& solidness investigation of PWM-voltage-type reversible rectifiers," IEEE Trans. Power Electron., vol. 45, no. 2, pp. 263-273, Apr. 1998

11. A.S.Yunus, A.Abu-Siada,\&M.A.S.Masoum, "Use of SMES unit to improve the high voltage- ride-through ability of DFIG framework associated during voltage swell," in Proc. IEEE Innov. Brilliant Grid Technol. Asia, 2011, pp. 1-6.

12. M. N. Eskander\&S. I. Amer, "Alleviation of voltage dunks \& swells in lattice associated wind vitality transformation frameworks," in Proc. ICROS-SICE Int. Joint Conf., 2009, pp. 885-890.

13. C. Wessels\&F. W. Fuchs, "High voltage ride through with FACTS for DFIG based breeze turbines," in Proc. thirteenth Eur. Conf. Power Electron. Appl., 2009, pp. 1-10.

14. C. Feltes, S. Engelhardt, J. Kretschmann, J. Fortmann, F. Koch,\&I Erlich, "High voltage ride through of DFIG-based breeze turbines," in Proc. IEEE Power Eng. Soc. Gen. Meet., 2008, pp. 1-8.

15. C.J.Liu, X.B.Huang, M.Chen,\&D.H.Xu, "Adaptable control of dc-interface voltage for doubly encouraged enlistment generato during matrix voltage swell," in Proc. IEEE Energy Convers. Congr. Expo. 2010, pp. 3091-3095.

16. R. Li, R. Spee, A. K. Wallace,\&G. C. Alexander, "Synchronous drive execution of brushless doubly-encouraged engines," IEEE Trans. Ind. Appl., vol. 30, no. 4, pp. 963-970, Jul./Aug. 1994.

17. V. T. Phan\&H. H. Lee, "Execution improvement of remain solitary DFIG frameworks with control of rotor\&burden side converters utilizing resounding controllers," IEEE Trans. Ind. Appl., vol. 48, no. 1, pp. 199-210, Jan./Feb. 2012. control usage for doubly-nourished machines," in Proc. IEEE Int. Conf. Ind. Electron. Contr. Instrum. 1993, pp. 1181-1186.

18. B.V.Gorti, G.C.Alexander,\&R.Spee, "Power balance contemplations forbrushlessdoublyfed machines," IEEETrans.EnergyConvers.,vol.11, no. 4, pp. 687-692, Dec. 1996.

19. R.Pena, R.Cardenas, E.Escobar, J.Clare,\&P.Wheeler, "Contro framework for lopsided activity of remain solitary doubly-bolstered acceptance generators," IEEE Trans. Vitality Convers., vol. 22, no. 2 , pp. 544-545, Jun. 2007 
20. C. Zhan, C. Fitzer, V. K. Ramachandaramurthy, A. Arulampalam, M. Barnes,\&N. Jenkins, "Programming stage bolted circle applied to dynamic voltage restorer (DVR)," in Proc. IEEE Power Eng.

21. Soc. Winter Meet., 2001, pp. 1033-1038.

22. X.Wang, Z.Wang,\& H.Lin, "A transient responsive current remuneration for load-side converter of BDFIG in remain solitary operation,"in Proc.IEEE Vitality Convers. Congr. Expo. 2015, pp. 1171-1177.

23. R.Li, A.Wallace,\& R.Spee, "Dynamic recreation of brushless doubly-sustained machines," IEEE Trans. Vitality Convers., vol. 6, no. 3, pp. 445-452, Sep. 1991.

24. X. Kong, Y. Yuan, P. Li, Y. Wang,\&J. Lin, "The plan \& investigation of the PI controller of threephase voltage source PWM rectifier," in Proc. IEEE Locale 10 Conf. TENCON, 2015, pp. 1-5.

25. D. Wang, H. Wang, J.Jia,\&Y. Zhang, "Responsive power control of doubly encouraged acceptance generator in wind ranch under low framework voltage," in Proc. IEEE Int. Conf. Crit. Framework., 2010, pp. 1-6.

26. H. W. van der Broeck, H. C. Skudelny,\&G. V. Stanke, "Examination \& acknowledgment of a heartbeat width modulator dependent on voltage space vector," IEEE Trans. Ind. Appl., vol. 24, no. 1, pp. 142-150, Jan./Feb. 1988

27. J. B. Hu\&Y. K. He, "Demonstrating \& control of matrix associated voltage sourced converters under summed up uneven activity conditions," IEEE Trans. Vitality Conv., vol. 23, no. 3, pp. 903-913, Sep. 2008.

28. J. W. Choi\&S.- K. Sul, "Quick present controller in three-stage ACDC help converter utilizing d-q pivot cross coupling," IEEE Trans. Power Electron., vol. 13, no. 1, pp. 179-185, Jan. 1998.

\section{AUTHORS PROFILE}

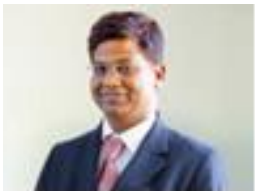

Dr. S. SIVA PRASAD, Professor of EEE Dept. in Vidya Jyothi Institute of Technology, Hyderabad. $\mathrm{He}$ has awarded Ph.D. Electrical Engineering in 2012 (February) from J.N.T.UNIVERSITY HYDERABAD And had his M.Tech with specialization of Power Electronics in 2003.He has obtained his B.Tech Degree in Electrical and Electronics Engineering from S V University. He is having 21 years of Experience and currently working as Professor \& HOD of EEE Dept. of Vidya Jyoti Institute of Technology, Aziz Nagar, and Hyderabad, India. He received Best Head of the Department award from ESN Award in the year 2019 and Bharat Vibhushan Samman Puraskar from The Economic and Human Resource Development Association in 2013 and received Young Investigator Award in 2012. He has published about 60 technical papers in International and National Journals and Conferences and filed one patent. He is Life member of ISTE and member of IEEE. His Research areas include Power Electronics \& Drives, PSD\&FACTS Controllers.

E-mail id:drsyamalasivaprasad@gmail.com

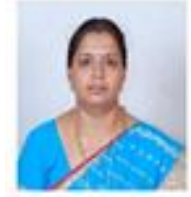

Dr. D. Lakshmi received her undergraduate degree in Electrical \& Electronics Engineering from Madras University in 1999 and postgraduate degree in Power Systems from Anna University in 2006. She finished her Ph.D. in 2018 from Anna University, Chennai at SSN College of Engineering, India working as an Associate Professor in Department of Electrical \& Electronics Engineering at AMET Deemed to be an University, Chennai. She has been teaching field for more than 18 years. She has published 21 papers in International Journals and more number of papers in Conference Proceedings and has supervised many undergraduate and postgraduate projects. Her research interests include deregulated power system, power generation \& operation, and power system control. Email id: lakshmiee@gmail.com

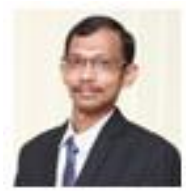

Dr. C. N. Ravi was born in Chennai, Tamil Nadu, in 1978. He received Bachelor of Engineering degree in Electrical and Electronics Engineering in the year 1999 from Crescent Engineering College, Chennai. Master of Engineering degree in Power Systems in the year 2006 from B.S.A.R Crescent Engineering College, and $\mathrm{Ph} . \mathrm{D}$. in power system optimization techniques from Sathyabama University, Chennai, Tamilnadu, India At present he is working as professor in Vidya Jyothi Institute Technology, Hyderabad, Telangana State, India. He has 15 years of teaching and 5 years of industrial experience. He received best teacher award in the year 2019 from ESN awards. He has guided several projects in the areas Power Electronics, Power Systems and Electric Drives. His area of interest is power system optimization, FACTS, power electronics and renewable energy system. Email id: dr.ravicn@gmail.com 